\title{
ANALISIS PROSES BISNIS SISTEM INFORMASI MANAJEMEN DOKUMEN PENDUKUNG BEBAN KERJA DOSEN DENGAN METODE PROTOYPING MODEL
}

\author{
Mirotus Solekhah ${ }^{10}{ }^{1)}$ dan Wahyuni Lasniah ${ }^{2)}$ \\ ${ }^{1}$ Perencanaan Wilayah dan Kota, Institut Teknologi Kalimantan \\ ${ }^{2}$ Sistem Informasi, Institut Teknologi Kalimantan \\ ${ }^{1,2}$ Jl. Soekarno-Hatta KM 15, Kota Balikpapan, 76127 \\ E-mail : mirotus.solekhah@gmail.com ${ }^{1)}$,wlasniah@gmail.com ${ }^{2)}$
}

\begin{abstract}
ABSTRAK
Dalam rangka pencapaian Good University Governance (GUC) bertujuan untuk mewujudkan Perguruan Tinggi yang akuntabel diperlukan sistem informasi pengelolaan dokumen beban kerja dosen (BKD). Pelaporan dan penyusunan BKD yang meliputi Pelaksanaan pendidikan, Pelaksanaan penelitian, Pelaksanaan pengabdian kepada masyarakat, Pengembangan diri, serta Penunjang tugas Dosen memerlukan dokumen pendukung yaitu Surat Keputusan (SK), Sertifikat, Laporan Penelitian dan Pengabdian masyarakat maupun surat keterangan. Institut Teknologi Kalimantan merupakan perguruan tinggi negeri yang memiliki lima jurusan yang salah satunya adalah Jurusan Matematika dam Teknologi Informasi (JMTI). Penyusunan dan pelaporan BKD di Lingkungan JMTI masih konvensional dan belum tertata dengan baik sehingga diperlukan sistem informasi manajemen dokumen pendukung BKD agar dapat memudahkan dosen dalam pengisian BKD. Sistem pengelolaan dokumen pendukung BKD sangat dibutuhkan agar seluruh dokumen pendukung BKD dapat dikelola dengan baik dan dapat mempermudah dosen ketika melakukan pelaporan BKD. Analisis proses sistem pengelolaan dokumen diperlukan untuk mengidentifikasi kebutuhan pengguna yang kemudian akan dilakukan implementasi algoritma sistem informasi. analisis sistem informasi ini dilakukan dengan metode prototyping model yang memiliki empat tahapan yaitu communication, quick plan and quick design, construction of prototype, dan evaluation. Pengujian hasil analisis sistem dilakukan dengan menggunakan metode system usability scale (SUS). Hasil penelitian ini berupa analisis proses bisnis dan prototipe sistem pengelolaan dokumen yang diberi nama "siment" dengan hasil pengujian bernilai good dan acceptable.
\end{abstract}

Kata Kunci: BKD, SUS, Prototipe Sistem, Prototyping Model, Analisis Sistem

\section{PENDAHULUAN}

Perkembangan teknologi informasi yang begitu pesat membuat banyak kegiatan terbiasa dibantu dengan menggunakan teknologi (Djawa dan Puspasari, 2015). Terutama penggunaan komputer dan internet. Penggunaan internet membuat data-data lebih mudah diakses dan lebih terpusat penyimpanannya (Sari, Luthfi dan Veren, 2018).

Instansi perguruan tinggi terdapat banyak elemen, salah satunya adalah dosen. Dosen merupakan salah satu elemen penting yang ada pada perguruan tinggi yang melaksanakan Tridharma Perguruan Tinggi. Tridharma Perguruan Tinggi yang selanjutnya disebut Tridharma adalah kewajiban Perguruan Tinggi untuk menyelenggarakan Pendidikan, penelitian, dan pengabdian kepada masyarakat (Sulistyowati dan Muazansyah, 2018; Mahani, Ma'rufi dan Indrayani, 2020). Segala bentuk kegiatan Tridharma perguruan Tinggi perlu dilakukan pelaporan agar setiap dosen dapat diukur beban kerjanya (Anisah $d k k$., 2020; Nugraha $d k k$., 2019).

Penelitian ini dilakukan pada Jurusan Matematika dan Teknologi Informasi Institut Teknologi Kalimantan.
Institut Teknologi Kalimantan khususnya JMTI (Jurusan Matematika dan Teknologi Informasi) memiliki 5 program studi dan 47 dosen. Seluruh dosen diwajibkan untuk melakukan pelaporan melalui Beban Kerja Dosen (BKD). Kegiatan yang dilaporkan pada BKD harus disertai dengan berkas pendukung, antara lain Surat Keputusan (SK), Sertifikat, Laporan Penelitian dan Pengabdian Masyarakat maupun surat keterangan. Berdasarkan hasil wawancara dan observasi di lapangan, saat ini penyusunan maupun pelaporan BKD masih dilakukan secara konvensional dan karena penyimpanan SK tidak terpusat membuat dosen sering kebingungan mencari dokumen pelengkap dari BKD. Saat pelaporan BKD data pendukung sering hilang karena tidak dilakukan pengarsipan dengan baik dan kemungkinan terjadi pergantian pegawai yang bertugas melakukan pengarsipan data pendukung BKD.

Berdasarkan permasalahan tersebut, peneliti melakukan analisis proses bisnis sistem informasi manajemen dokumen pendukung beban kerja dosen dan melakukan perancangan prototipe atau rancangan antar muka dari sistem tersebut. Hasil penelitian ini berupa analisis proses bisnis dan prototipe sistem pengelolaan 
dokumen yang diberi nama "siment", yang diharapkan dapat menjadi dasar dalam melakukan pengembangan atau development sistem tersebut agar sistem yang dihasilkan dapat sesuai dengan kebutuhan pengguna dan hasil analisis dan rancangan antar muka yang dihasilkan dapat memudahkan tahap development system (Nacheva, 2017).

Tujuan yang ingin dicapai dalam penelitian ini adalah menghasilkan analisis sistem dan prototipe sistem informasi manajemen pengelolaan dokumen yang dibutuhkan oleh pengguna yang dapat mempermudah pelaporan Beban Kerja Dosen.

Manfaat yang diberikan dengan adanya penelitian ini yaitu Institut Teknologi Kalimantan dapat memiliki analisis sistem dan prototipe sistem informasi manajemen pengelolaan dokumen beban kerja dosen berbasis website yang sesuai dengan kebutuhan pengguna yang ada di Institut Teknologi Kalimantan khususnya di Lingkungan Jurusan Matematika dan Teknologi Informasi. Dengan adanya pengelolaan dokumen beban kerja dosen yang baik harapannya dapat mewujudkan prinsip Good University Governance yaitu Responsibility (tanggung jawab) and Fairness (adil).

\section{RUANG LINGKUP}

Berdasarkan latar belakang, penulis mengangkat 2 (dua) masalah pada penelitian ini. Masalah yang diangkat adalah:

1. Pengelolaan dokumen pendukung BKD yang masih buruk menyebabkan kesulitan dosen dalam mengumpulkan berkas pendukung BKD.

2. Belum adanya sistem pengelolaan dokumen pendukung BKD di lingkungan Jurusan Matematika dan Teknologi Informasi ITK.

Agar penelitian ini dapat terukur dengan baik, maka perlu adanya batasan-batasan penelitian. Batasan penelitian ini adalah penelitian ini hanya akan dilakukan pada lingkungan Jurusan Matematika dan Teknologi Informasi Institut Teknologi Kalimantan.

Hasil dari penelitian ini berupa analisis proses bisnis dan prototipe dari sistem informasi manajemen dokumen pendukung beban kerja dosen.

\section{BAHAN DAN METODE}

Penelitian ini dilakukan dengan melakukan analisis kebutuhan sistem informasi dan menggunakan metode prototyping model, selanjutnya prototipe yang dihasilkan sesuai dengan analisis dilakukan pengujian dengan metode SUS kepada pengguna.

\subsection{Sistem Informasi}

Sistem informasi yang dapat didefinisikan secara teknis sebagai seperangkat komponen yang saling terkait yang mengumpulkan (atau mengambil), memproses, menyimpan, dan mendistribusikan informasi untuk mendukung pengambilan keputusan dan pengendalian dalam suatu organisasi (Ardhiyani dan Mulyono, 2018; Muslim, 2018).

\subsection{Analisis Sistem Informasi}

Analisis sistem merupakan tahapan paling awal dari pengembangan sistem yang menjadi fondasi menentukan keberhasilan sistem informasi yang dihasilkan nantinya (Muhidin, Kharie dan Kubais, 2019; Rahmawati dan Bachtiar, 2018).

\subsection{Prototyping Model}

Prototyping model merupakan metode yang digunakan untuk melakukan pembuatan prototipe sistem informasi ini. Prototyping model merupakan metode pengembangan sistem yang langsung menerapkan hasil analisis kepada sistem tanpa menunggu sistem benarbenar selesai (Wijaya, 2019).Prototyping model dilakukan dengan merancang prototipe aplikasi, dievaluasi oleh pengguna, dan selanjutnya dilakukan perbaikan prototipe (Nugraha dan Syarif, 2018).

Dibuatnya sebuah prototipe bagi pengembang sistem bertujuan untuk mengumpulkan informasi dari pengguna sehingga pengguna dapat berinteraksi dengan model prototyping yang dikembangkan, sebab prototype menggambarkan versi awal dari sistem untuk kelanjutan sistem sesungguhnya yang lebih besar (Purnomo, 2017; Yoko, Adwiya dan Nugraha, 2019). Tahapan prototyping model dilakukan terus-menerus sampai didapatkan hasil yang sesuai dengan kebutuhan pengguna.

Pembangunan prototipe sistem informasi dilakukan dengan metode prototyping model, dimana proses ini dimulai dengan melakukan pengumpulan data, melakukan analisis kebutuhan sistem dan membuat prototipe sistem seperti yang terdapat pada Gambar 1 .

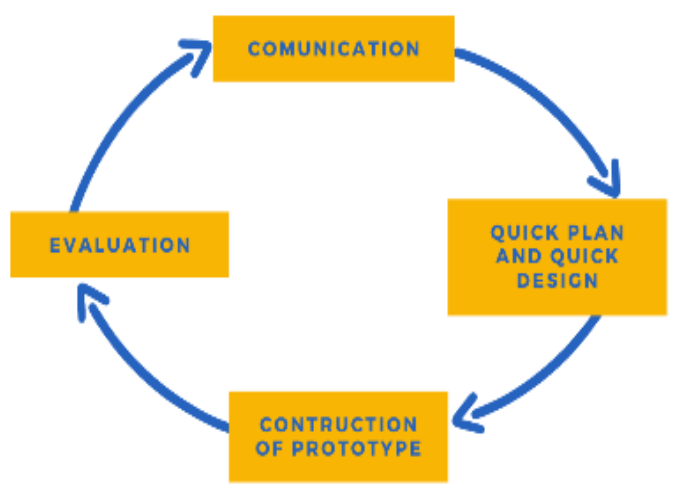

Gambar 1. Alur Prototyping Model

Sumber: (Ardhiyani dan Mulyono, 2018)

Communication merupakan tahapan melakukan pengumpulan data melalui wawancara dan observasi. Seluruh data yang selanjutnya akan digunakan sebagai dasar melakukan analisis sistem akan dikumpulkan pada tahapan ini. Tahapan ini dilakukan agar desain sistem 
yang dihasilkan dapat sesuai dengan kebutuhan pengguna.

Quick plan and quick design adalah tahapan melakukan rancangan umum dan analisis yang kemudian akan diserahkan kepada stakeholder atau pengguna. Analisis yang dibutuhkan antara lain: kebutuhan fungsionalitas, kebutuhan non-fungsionalitas, use case diagram, activity diagram, dan desain antarmuka sistem.

Construction of Prototype merupakan tahapan membangun prototipe sesuai dengan hasil analisis yang telah dikomunikasikan dengan pengguna. Pada tahapan ini juga hasil prototipe dilakukan perbaikan apabila pengguna telah memberikan masukan atau ada prototipe yang kurang sesuai dengan kebutuhan pengguna.

Evaluation pada tahapan ini pengguna melakukan percobaan atau melalui evaluasi terhadap hasil prototipe yang telah dibangun. Kemudian apabila masih ada yang kurang sesuai hasil prototipe akan dilakukan perbaikan dan di evaluasi kembali oleh pengguna.

\subsection{Entity Relationship Diagram (ERD)}

Entity Relationship Diagram (ERD) digunakan untuk menggambarkan model entity relationship. ERD berisikan himpunan entitas dan himpunan relasi. Masingmasing entitas dilengkapi dengan atribut-atribut yang menjelaskan seluruh komponen dari dunia nyata berdasarkan hasil analisis (Sukmaindrayana dan Sidik, 2017).

\subsection{UML (Unified Modelling Language)}

UML (Unified Modelling Language) merupakan sekelompok alat-alat yang pada umumnya berupa diagram untuk merancang atau memodelkan bagaimana sistem tersebut bekerja, bagaimana pengguna bisa berinteraksi menggunakan sistem, bagaimana tata cara kerja dari sistem, \& fitur-fitur yg masih ada pada sebuah sistem yang nantinya akan diimplementasikan. UML penting digunakan oleh analis sistem karena berbagai macam manfaat yang beragam yaitu dapat manajemen kompleksitas dari sistem, mendeteksi kesalahan yang mungkin terjadi saat diimplementasikan, menjelaskan tata kerja dari sistem kepada para pihak yang berkepentingan (Hendy, 2019).

Pemodelan memberikan gambaran yang jelas mengenai sistem yang akan dibangun baik dari sisi struktural ataupun fungsional. UML dapat diterapkan pada semua model pengembangan, tingkatan siklus sistem, dan berbagai macam domain aplikasi. Dalam UML terdapat konsep semantik, notasi, dan panduan masing-masing diagram. UML juga memiliki bagian statis, dinamis, ruang lingkup, dan organizational. UML bertujuan menyatukan teknik-teknik pemodelan berorientasi objek menjadi standarisasi.(Akil, 2016).

\subsection{SUS (System Usability Scale)}

Pengukuran tingkat kegunaan atau usability dilakukan untuk menilai bagaimana interaksi antara pengguna dengan aplikasi atau prototipe, apakah berjalan dengan baik atau tidak (Huda, 2019). System Usability Scale (SUS) merupakan pengukuran tingkat usability yang dilakukan dengan menggunakan bantuan kuesioner. SUS memiliki beberapa keunggulan antara lain: SUS dapat digunakan dengan mudah karena hasilnya berupa angka 0-100, SUS tidak membutuhkan perhitungan yang rumit, SUS tersedia secara gratis, SUS terbukti valid dan reliable (Aprilia, Santoso dan Ferdiana, 2015).

Kuesioner yang digunakan untuk melakukan pengujian SUS terdiri dari 10 pertanyaan, masing-masing memiliki 5 poin sebagai tanggapan atau bisa dianggap sebagai "Sangat Tidak Setuju" sampai "Sangat Setuju", semakin besar skor berarti semakin baik nilai usability dari sistem yang diuji (Aprilia, Santoso dan Ferdiana, 2015).

Perhitungan hasil pengujian perangkat lunak dengan metode SUS dilakukan sesuai dengan aturan SUS. Setiap pertanyaan dengan nomor ganjil maka skala yang diberikan oleh responden dikurang 1 dan setiap pertanyaan dengan nomor genap maka 5 akan dikurangi dengan skala yang diberikan oleh responden. Setelah nilai yang telah didapat sudah dijumlahkan maka nilai tersebut dikalikan dengan 2,5. Kemudian dicari nilai rata-rata dari nilai yang didapat dari seluruh responden (Ependi, Panjaitan dan Hutrianto, 2017)

Sesuai dengan Gambar 2 System Usability Scale (SUS) memiliki tiga kategori yaitu not acceptable, marginal, dan acceptable. Kategori ini yang dapat menggambarkan bagaimana interaksi antara pengguna dengan hasil aplikasi atau prototipe yang telah dibangun.

\section{System Usability Score}

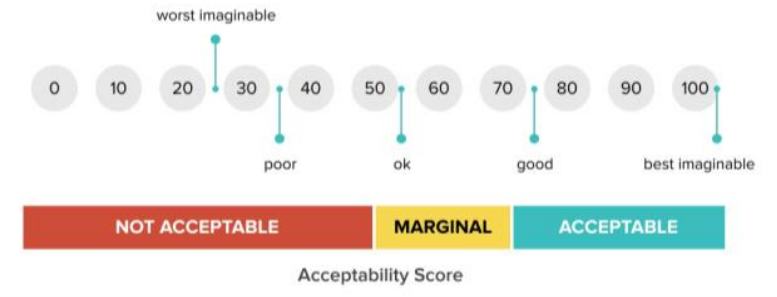

Gambar 2. Skala Nilai SUS

Sumber: https://medium.com/

\section{PEMBAHASAN}

Analisis proses bisnis sistem informasi manajemen dokumen pendukung BKD ditinjau dari berbagai elemen. Hasil pengumpulan data yang dilakukan pada lingkungan JMTI ITK menghasilkan:

1. Beberapa dosen mengalami kesulitan mengakses informasi terkini seputar berkas pendukung BKD.

2. Dibutuhkan waktu yang cukup lama untuk mengumpulkan dokumen-dokumen pendukung dalam persiapan pengajuan BKD.

3. Diperlukan sistem pengelolaan dokumen pendukung BKD di lingkungan Jurusan Matematika dan Teknologi Informasi ITK. 
Berdasarkan permasalahan tersebut, maka dirancang proses bisnis sistem informasi seperti yang terdapat pada Gambar 3.

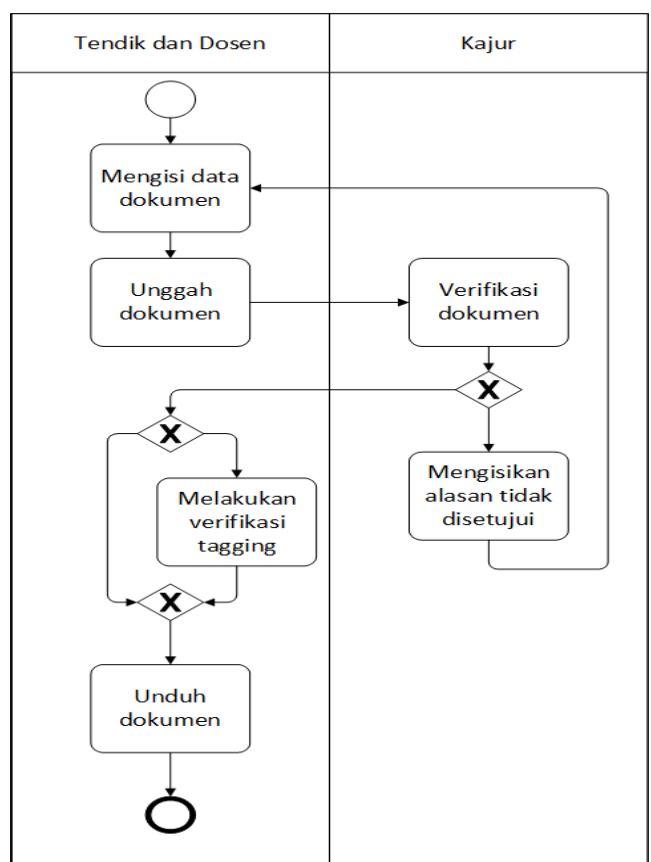

Gambar 3. Proses Bisnis Sistem Informasi Manajemen Dokumen Pendukung BKD

Berdasarkan Gambar 3, peneliti melakukan penentuan kebutuhan fungsionalitas pada Tabel 1 dan non-fungsionalitas pada Tabel 2 sesuai dengan hasil analisis proses bisnis. Terdapat 8 fitur atau kebutuhan fungsionalitas dan 2 kebutuhan non-fungsionalitas.

Kebutuhan non fungsional merupakan kebutuhan yang menggambarkan bagaimana sistem berkerja ke depannya. Dalam menentukan kebutuhan non fungsional tidaklah mudah, karena harus mengerti karakteristik dan batasan dari sistem (Aziiza dan Fadhilah, 2020). Sedangkan kebutuhan fungsional adalah kebutuhan yang berisi proses-proses apa saja yang nantinya dilakukan oleh sistem (Luh $d k k .$, 2018)

Tabel 1. Kebutuhan Fungsionalitas

\begin{tabular}{|c|l|}
\hline Kode & \multicolumn{1}{c|}{ Deskripsi } \\
\hline FS-01 & $\begin{array}{l}\text { Sistem harus menyediakan fitur login untuk } \\
\text { pengguna. }\end{array}$ \\
\hline FS-02 & $\begin{array}{l}\text { Sistem harus menyediakan fitur pengelolaan } \\
\text { data dokumen (menambah, mengubah, } \\
\text { menghapus). }\end{array}$ \\
\hline FS-03 & $\begin{array}{l}\text { Sistem harus menyediakan fitur tagging pada } \\
\text { setiap dokumen. }\end{array}$ \\
\hline FS-04 & $\begin{array}{l}\text { Sistem harus menyediakan fitur verifikasi } \\
\text { dokumen. }\end{array}$ \\
\hline FS-05 & Sistem harus menyediakan fitur kelola profil. \\
\hline FS-06 & $\begin{array}{l}\text { Sistem harus menyediakan fitur lihat dan } \\
\text { unduh dokumen. }\end{array}$ \\
\hline
\end{tabular}

\begin{tabular}{|l|l|}
\hline FS-07 & Sistem harus menyediakan fitur notifikasi. \\
\hline FS-08 & $\begin{array}{l}\text { Sistem harus menyediakan fitur verifikasi } \\
\text { tagging. }\end{array}$ \\
\hline
\end{tabular}

Tabel 2. Kebutuhan Non-Fungsionalitas

\begin{tabular}{|c|l|}
\hline Kode & \multicolumn{1}{|c|}{ Deskripsi } \\
\hline NFS-01 & $\begin{array}{l}\text { Software harus memiliki usability yang tinggi } \\
\text { sehingga mudah digunakan. }\end{array}$ \\
\hline NFS-02 & $\begin{array}{l}\text { Software harus memiliki tampilan yang } \text { user } \\
\text { friendly. }\end{array}$ \\
\hline
\end{tabular}

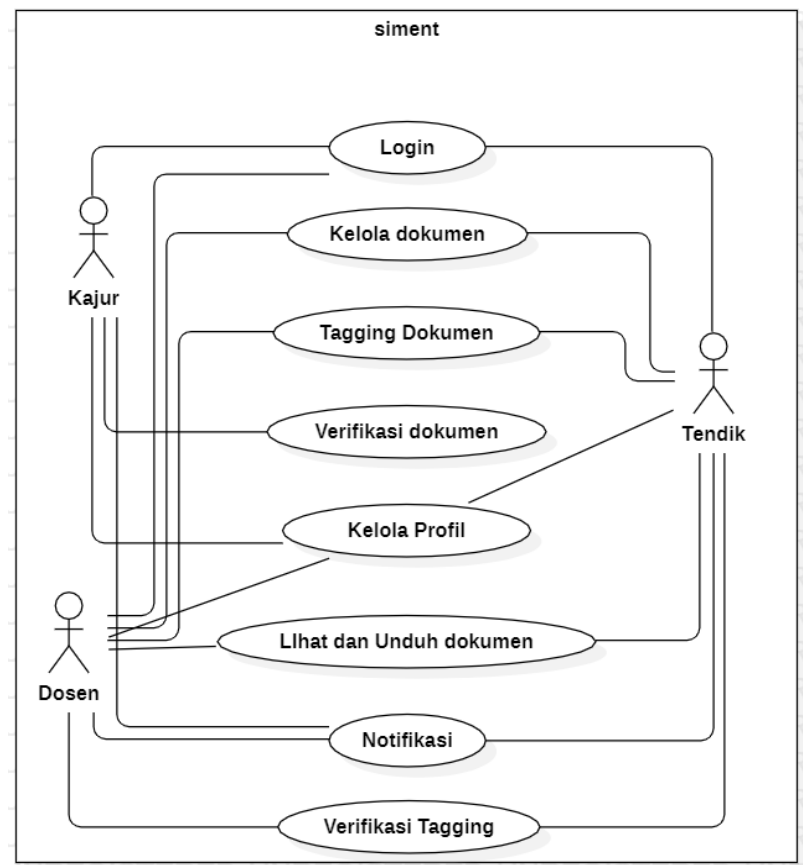

Gambar 4. Use case diagram

Pada Gambar 4, peneliti melakukan perancangan use case diagram berdasarkan hasil analisis sebelumnya. Berdasarkan Gambar 4, pada diagram terdapat 3 aktor atau pengguna dan 8 fitur pada sistem dengan penjelasan terdapat pada Tabel 3 dan Tabel 4 .

Tabel 3. Daftar Dan Deskripsi Pengguna Sistem

\begin{tabular}{|c|l|}
\hline Nama Aktor & \multicolumn{1}{c|}{ Deskripsi } \\
\hline Ketua Jurusan & $\begin{array}{l}\text { Aktor ini merupakan dosen di JMTI yang } \\
\text { juga memiliki tugas tambahan sebagai } \\
\text { ketua jurusan dan telah memiliki akun } \\
\text { dengan akses sebagai ketua jurusan di } \\
\text { siment. }\end{array}$ \\
\hline Dosen & $\begin{array}{l}\text { Aktor ini merupakan dosen di JMTI yang } \\
\text { telah memiliki akun dengan akses sebagai } \\
\text { dosen di siment. }\end{array}$ \\
\hline Tenaga & $\begin{array}{l}\text { Aktor ini merupakan tenaga kependidikan } \\
\text { di JMTI yang telah memiliki akun dengan } \\
\text { akses sebagai tenaga kependidikan di } \\
\text { siment. }\end{array}$ \\
\hline
\end{tabular}


Tabel 4. Deskripsi fitur sistem

\begin{tabular}{|c|c|c|}
\hline Kode & Deskripsi & Aktor \\
\hline UC-01 & $\begin{array}{l}\text { Login } \\
\text { Deskripsi: } \\
\text { Sistem akan menampilkan halaman } \\
\text { login dan aktor dapat login sesuai } \\
\text { username dan password yang dimiliki. }\end{array}$ & $\begin{array}{l}\text { Kajur, } \\
\text { Dosen, } \\
\text { Tendik }\end{array}$ \\
\hline UC-02 & $\begin{array}{l}\text { Kelola data dokumen } \\
\text { Deskripsi: } \\
\text { Sistem akan menampilkan halaman } \\
\text { pengelolaan data dokumen dan aktor } \\
\text { dapat melakukan menambah, } \\
\text { mengubah, dan hapus data dokumen. }\end{array}$ & $\begin{array}{l}\text { Dosen, } \\
\text { Tendik }\end{array}$ \\
\hline UC-03 & $\begin{array}{l}\text { Tagging Dokumen } \\
\text { Deskripsi: } \\
\text { Sistem akan menampilkan halaman } \\
\text { tagging dokumen dan aktor dapat } \\
\text { melakukan tag kepada setiap orang } \\
\text { yang terkait dengan dokumen tersebut. }\end{array}$ & $\begin{array}{l}\text { Dosen, } \\
\text { Tendik }\end{array}$ \\
\hline UC-04 & $\begin{array}{l}\text { Verifikasi dokumen } \\
\text { Deskripsi: } \\
\text { Sistem akan menampilkan halaman } \\
\text { verifikasi dokumen dan aktor dapat } \\
\text { melakukan verifikasi atau persetujuan } \\
\text { mengenai dokumen tersebut. }\end{array}$ & Kajur \\
\hline UC-05 & $\begin{array}{l}\text { Kelola Profil } \\
\text { Deskripsi: } \\
\text { Sistem akan menampilkan halaman } \\
\text { kelola profil sehingga pengguna bisa } \\
\text { mengubah data pribadinya. }\end{array}$ & $\begin{array}{l}\text { Kajur, } \\
\text { Dosen, } \\
\text { Tendik }\end{array}$ \\
\hline UC-06 & $\begin{array}{l}\text { Lihat dan unduh dokumen } \\
\text { Deskripsi: } \\
\text { Sistem akan menampilkan halaman } \\
\text { lihat dan unduh dokumen sehingga } \\
\text { aktor dapat melakukan unduh dokumen. }\end{array}$ & $\begin{array}{l}\text { Kajur, } \\
\text { Dosen, } \\
\text { Tendik }\end{array}$ \\
\hline UC-07 & $\begin{array}{l}\text { Notifikasi } \\
\text { Deskripsi: } \\
\text { Sistem akan menampilkan halaman } \\
\text { notifikasi apabila aktor menerima tag } \\
\text { atau terdapat dokumen yang perlu } \\
\text { dilakukan verifikasi. }\end{array}$ & $\begin{array}{l}\text { Kajur, } \\
\text { Dosen, } \\
\text { Tendik }\end{array}$ \\
\hline UC-08 & $\begin{array}{l}\text { Verifikasi Tagging } \\
\text { Deskripsi: } \\
\text { Sistem akan menampilkan halaman } \\
\text { verifikasi tagging dan aktor dapat } \\
\text { melakukan verifikasi dokumen apabila } \\
\text { dokumen tersebut benar terkait dengan } \\
\text { dirinya. }\end{array}$ & $\begin{array}{l}\text { Dosen, } \\
\text { Tendik }\end{array}$ \\
\hline
\end{tabular}

Agar dapat memudahkan programmer saat melakukan implementasi atau pembuatan sistem informasi, maka dilakukan perancangan activity diagram atau alur dari sistem informasi. Terdapat 8 alur sistem sesuai dengan fitur yang akan disediakan oleh sistem. Pada Gambar 5 merupakan salah satu activity diagram tagging dokumen. Pada aplikasi siment, pengguna dapat melakukan tagging pada dokumen sehingga pengguna dapat melihat dokumen mana saja yang berkaitan dengan dirinya.

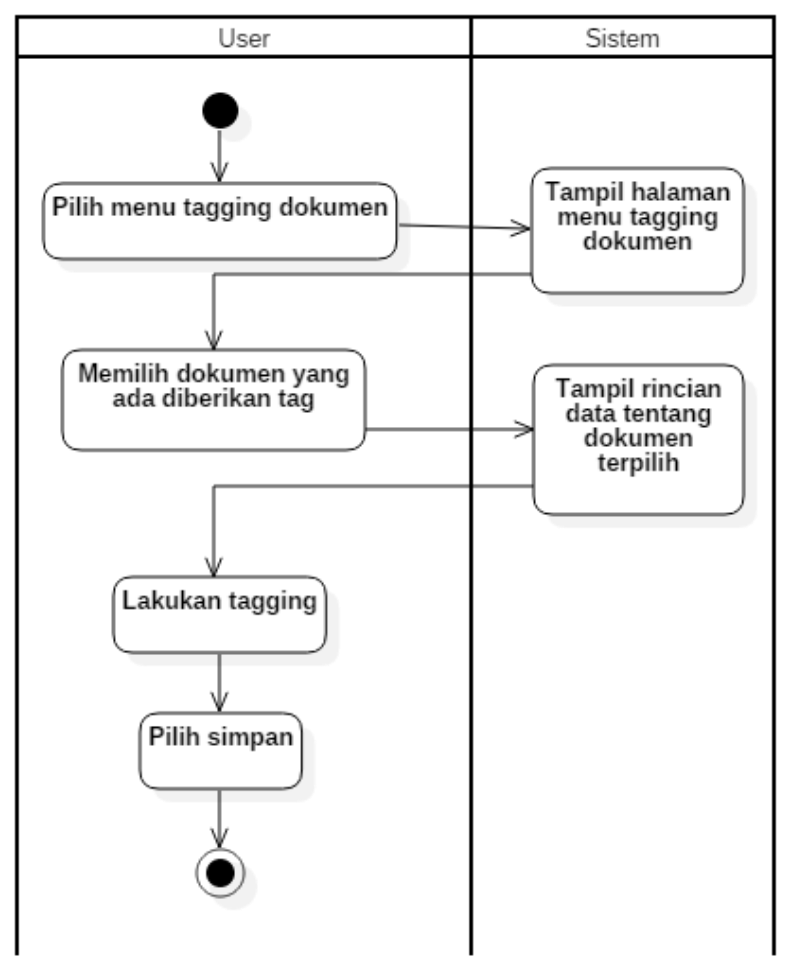

\section{Gambar 5. Activity Diagram Tagging Dokumen}

Untuk melengkapi hasil analisis proses bisnis, peneliti juga melakukan perancangan tampilan antar muka atau user interface (UI). Agar sistem yang dirancang dapat berguna dan memudahkan penggunanya, maka peneliti berusaha membuat rancangan UI dari sistem baik mungkin. Rancangan UI dibuat dengan bantuan aplikasi figma dan justinmind. Dengan bantuan alat tersebut peneliti dapat menjelaskan alur dari sistem dan pengguna juga dapat terbayang mengenai alur penggunaan sistem apabila sistem ini telah diimplementasikan.

Pada Gambar 6 merupakan halaman beranda atau halaman depan dari sistem. Pengguna dapat menggunakan fitur-fitur yang tersedia. Apabila pengguna kesulitan, pengguna dapat melihat panduan dari penggunaan sistem pada menu yang telah disediakan. 

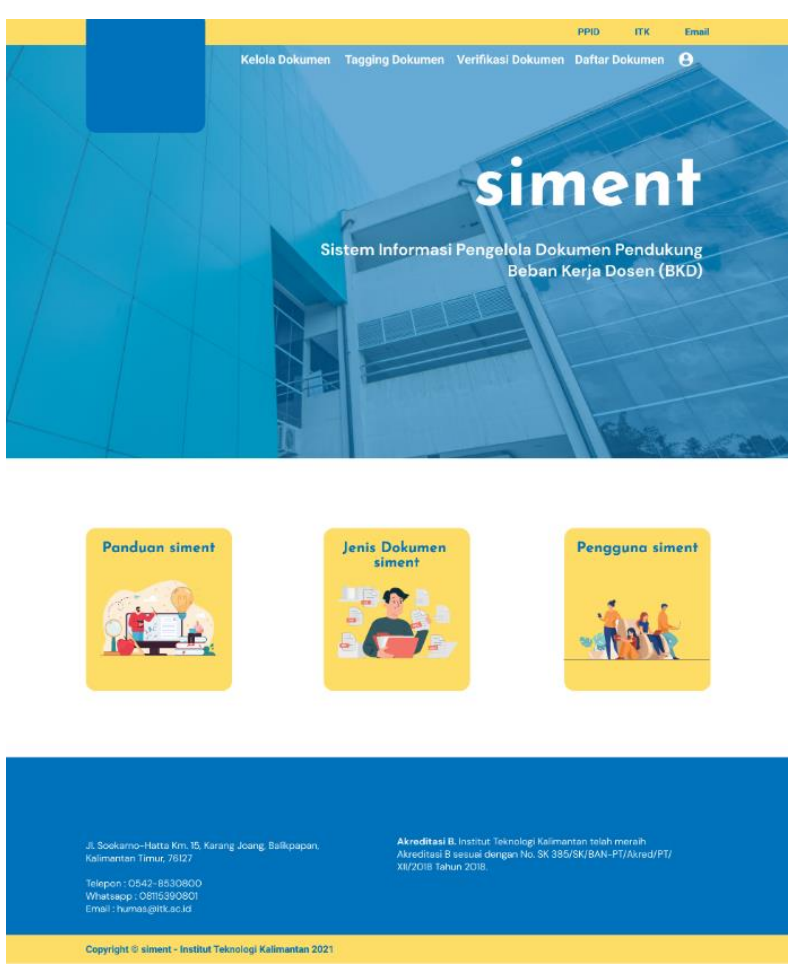

\section{Gambar 6. Halaman Awal}

Pada Gambar 7, merupakan tampilan halaman masuk akun atau login pengguna. Pengguna dapat memasukkan username dan password sebagai identitas setiap pengguna. Selanjutnya sistem akan melakukan pemeriksaan data yang dimasukkan oleh pengguna apabila sesuai maka pengguna dapat menggunakan seluruh fitur-fitur yang ada pada aplikasi siment sesuai dengan role atau jenis akun nya. Sedangkan apabila data yang dimasukkan mengguna tidak sesuai maka akan tampil seperti pada Gambar 8 dan pengguna hanya bisa menggunakan beberapa fitur yang terdapat pada aplikasi siment. Salah satunya fitur daftar dokumen, pada fitur tersebut pengguna dapat melakukan unduh dokumen dan dapat melihat rincian informasi mengenai dokumen terkait.

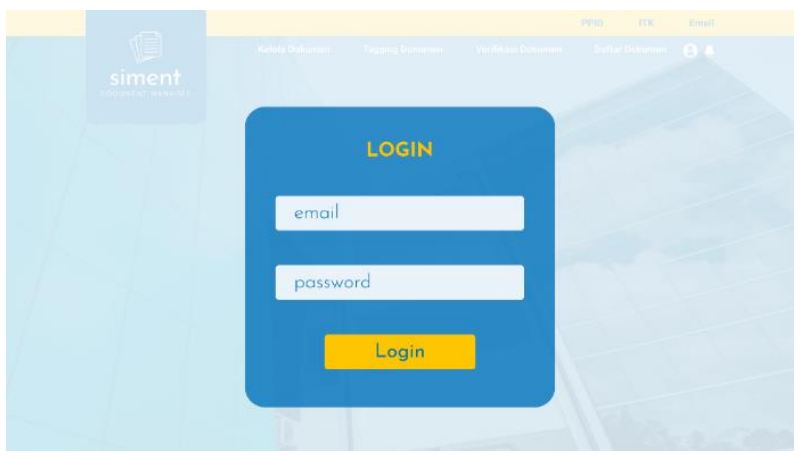

Gambar 7. Halaman Login

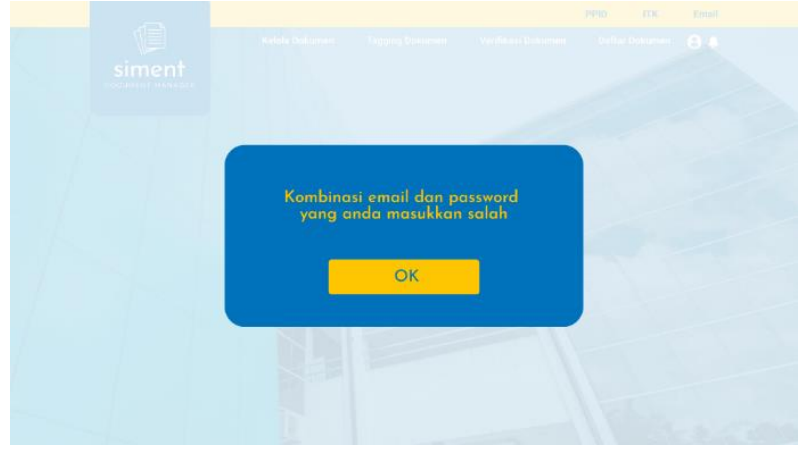

\section{Gambar 8. Halaman Peringatan}

Pada Gambar 9, Gambar 10, Gambar 11, dan Gambar 12 merupakan halaman kelola dokumen. Pengguna dapat melihat dokumen yang telah diunggah oleh pengguna yang bersangkutan.

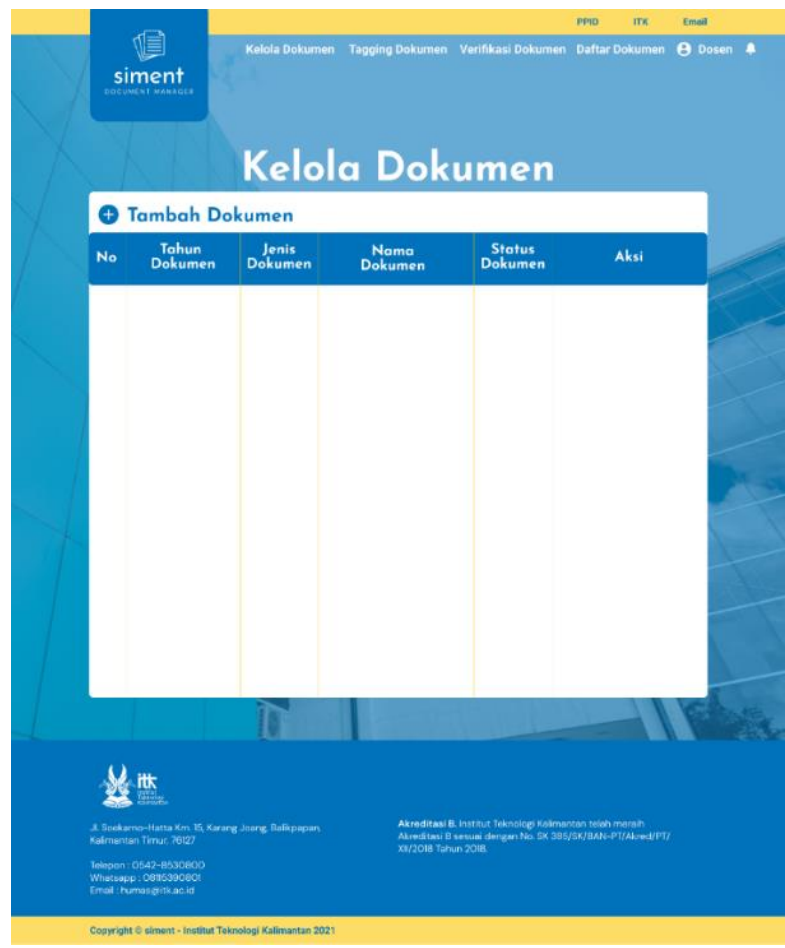

Gambar 9. Halaman Kelola Dokumen

Gambar 10 adalah tampilan antar muka fitur tambah dokumen. Pengguna dapat melakukan unggah dokumen dengan mengisi data-data yang terkait dengan dokumen tersebut. 


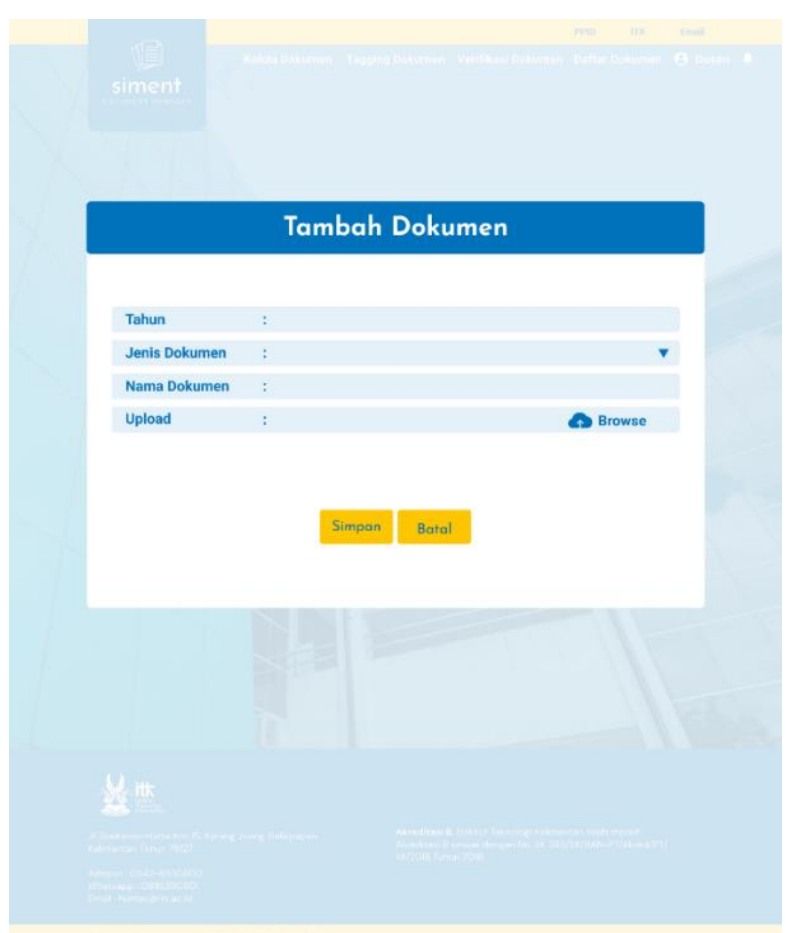

Gambar 10. Halaman Tambah Dokumen

Gambar 11 merupakan tampilan ubah dokumen. Pengguna dapat melakukan ubah dokumen apabila terdapat kekeliruan saat melakukan pengisian data awal atau terdapat anjuran perbaikan dari hasil verifikasi yang dilakukan oleh ketua jurusan.

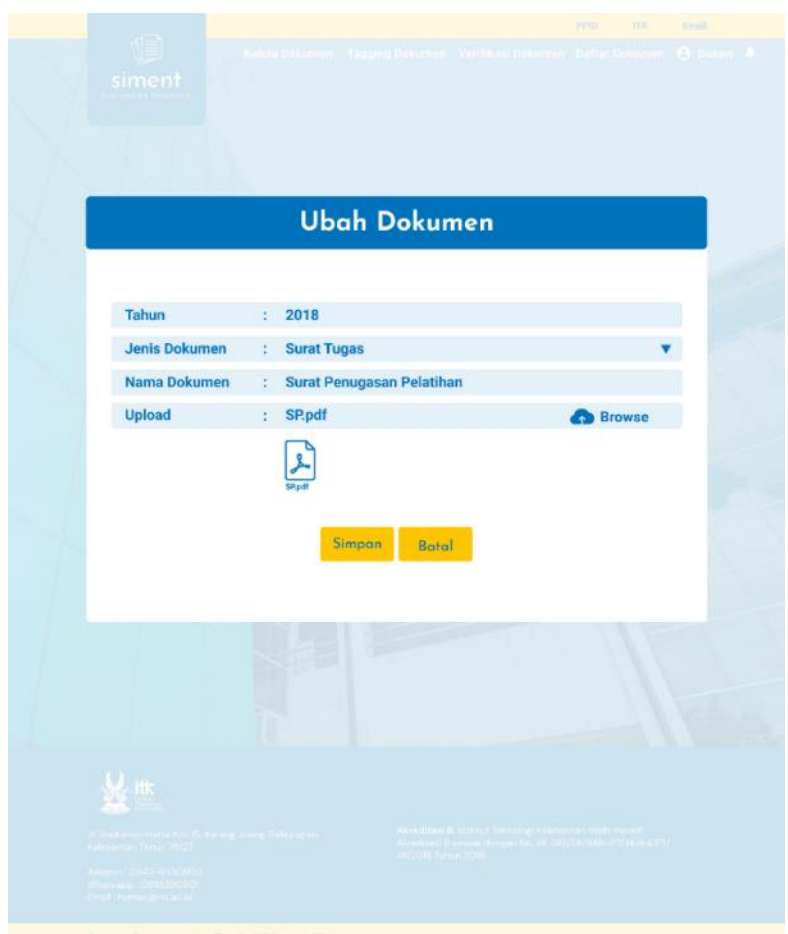

Gambar 11. Halaman Ubah Dokumen
Pada Gambar 12 merupakan halaman hapus dokumen yang telah diunggah oleh pengguna.

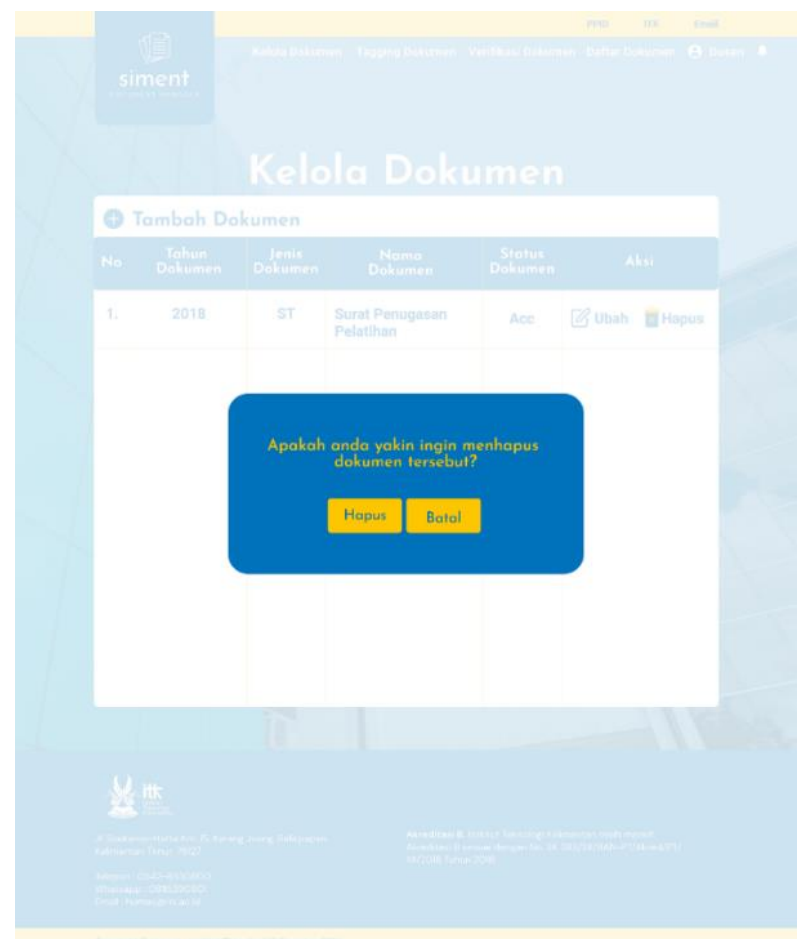

\section{Gambar 12. Halaman Hapus Dokumen}

Pada penelitian ini, dilakukan pengujian dengan metode SUS. Pengujian dilakukan kepada dosen, tenaga kependidikan, dan ketua jurusan. Dengan hasil pengujian pada Tabel 5.

Tabel 5. Hasil Pengujian SUS

\begin{tabular}{|c|c|c|c|c|c|c|c|c|c|c|c|c|}
\hline \multirow{2}{*}{ Peran } & \multicolumn{10}{|c|}{ Questions } & \multirow{2}{*}{ 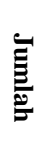 } & \multirow{2}{*}{$\times 2.5$} \\
\hline & 1 & 2 & 3 & 4 & 5 & 6 & 7 & 8 & 9 & 10 & & \\
\hline $\begin{array}{l}\text { Ketua } \\
\text { Jurusan }\end{array}$ & 4 & 2 & 5 & 5 & 4 & 1 & 5 & 1 & 5 & 1 & 33 & 82.5 \\
\hline $\begin{array}{l}\text { Tenaga } \\
\text { Kepen- } \\
\text { didikan }\end{array}$ & 5 & 2 & 4 & 4 & 4 & 2 & 5 & 2 & 4 & 2 & 33 & 82.5 \\
\hline Dosen & 4 & 1 & 5 & 5 & 4 & 2 & 3 & 1 & 4 & 4 & 27 & 67.5 \\
\hline \multicolumn{12}{|c|}{ Nilai rata-rata } & 77.5 \\
\hline
\end{tabular}

Berdasarkan data yang ada pada Tabel 5, hasil pengujian SUS mendapatkan nilai 77.5. Sesuai aturan yang terdapat pada Gambar 2 maka hasil penelitian ini bernilai good dan acceptable.

\section{KESIMPULAN}

Analisis proses bisnis perlu dilakukan sebelum melakukan implementasi sistem, agar sistem yang 
dihasilkan dapat sesuai dengan kebutuhan dari pengguna. Analisis proses bisnis dan perancangan prototipe dilakukan dengan beberapa tahapan dan menghasilkan beberapa hasil analisis berupa penentuan kebutuhan fungsionalitas, non-fungsionalitas, aktor, proses bisnis yang di gambarkan dengan BPMN diagram, use case diagram, activity diagram, dan peneliti juga melakukan perancangan antar muka atau user interface. Hasil analisis proses bisnis dapat mengidentifikasi dan modifikasi proses yang ada untuk perbaikan di masa yang akan datang. Kemudian, dapat mewujudkan sistem yang dapat membantu pengguna melakukan pengelolaan dokumen BKD. Dengan proses bisnis yang baik, tidak ada kinerja yang terhambat, dokumen dapat terarsipkan dengan baik, dan dapat mengurangi waktu pengerjaan pelaporan BKD. Hasil dari pengujian dengan metode SUS, hasil analisis sistem yang telah dilakukan bernilai good dan acceptable.

\section{SARAN}

Salah satu saran kepada penelitian dengan judul atau topik serupa adalah, dapat melakukan perancangan sistem dengan menggunakan metode lainnya dan dapat melakukan pengumpulan data melalui lebih banyak calon pengguna sistem.

\section{DAFTAR PUSTAKA}

Akil, I. (2016) "Rekayasa Perangkat Lunak Dengan Model Unified Process Studi Kasus: Sistem Informasi Journal," Jurnal Pilar Nusa Mandiri, 12(1), hal. 11. Tersedia pada: http://ejournal.nusamandiri.ac.id/index.php/pilar/a rticle/view/253.

Anisah, A. dkk. (2020) "Simulasi Database Beban Kerja Dosen Perguruan Tinggi Menggunakan Dimensional Modeling," Simetris: Jurnal Teknik Mesin, Elektro dan Ilmu Komputer, 11(1), hal. 177-184. doi: 10.24176/simet.v11i1.3855.

Aprilia, I., Santoso, P. I. dan Ferdiana, R. (2015) "Pengujian Usability Website Menggunakan System Usability Scale," JURNAL IPTEKKOM: Jurnal Ilmu Pengetahuan \& Teknologi Informasi, 17(1), hal. 31. doi: 10.33164/iptekkom.17.1.2015.31-38.

Ardhiyani, R. P. dan Mulyono, H. (2018) “Analisis Dan Perancangan Sistem Informasi Pariwisata Berbasis Web Sebagai Media Promosi Pada Kabupaten Tebo," Jurnal Manajemen Sistem Informasi, 3(1), hal. 952-972.

Aziiza, A. A. dan Fadhilah, A. N. (2020) "Analisis Metode Identifikasi dan Verifikasi Kebutuhan Non Fungsional," Applied Technology and Computing Science Journal, 3(1), hal. 13-21. doi: 10.33086/atcsj.v3i1.1623.

Djawa, M. K. dan Puspasari, D. (2015) "Implementasi Aplikasi Sistem Informasi Manajemen Kepegawaian (SIMPEG) Untuk Mendukung EGoverment Pada Badan Kepegawaian Daerah
(BKD) Provinsi Jawa Timur," Jurnal Administrasi Perkantoran, 3, hal. 1-15. Tersedia pada:

https://jurnalmahasiswa.unesa.ac.id/index.php/jpa p/article/view/12522/11560.

Ependi, U., Panjaitan, F. dan Hutrianto, H. (2017) "System Usability Scale Antarmuka Palembang Guide Sebagai Media Pendukung Asian Games XVIII," Journal of Information Systems Engineering and Business Intelligence, 3(2), hal. 80. doi: 10.20473/jisebi.3.2.80-86.

Hendy (2019) "Pemodelan Sistem Menggunakan UML (Unified Modelling Language)," System Modelling, (July), hal. 1-5. Tersedia pada: https://www.researchgate.net/publication/334562 380.

Huda, N. (2019) "Implementasi Metode Usability Testing Dengan System Usability Scale Dalam Penilaian Website Rs Siloam Palembang," Klik Kumpulan Jurnal Ilmu Komputer, 6(1), hal. 36. doi: 10.20527/klik.v6i1.177.

Luh, N. dkk. (2018) "Analisis Kebutuhan Fungsional Sistem Administrasi Sebagai," 2018(Sentika), hal. 23-24.

Mahani, D. S., Ma'rufi, I. dan Indrayani, R. (2020) "Beban Kerja Mental dan Pendapatan dengan Kebahagiaan di Tempat Kerja Pada Dosen di Universitas Jember,' Ikesma, 16(1), hal. 16. doi: 10.19184/ikesma.v16i1.16002.

Muhidin, R., Kharie, N. F. dan Kubais, M. (2019) "Analisis Dan Perancangan Sistem Informasi Pada Sma Negeri 18 Halmahera Selatan Sebagai Media Promosi Berbasis Web Analysis and Information System Design in Sma Negeri 18 South Halmahera As Media Promotion of WebBased," IJIS-Indonesia Journal on Information System, 4(April), hal. 69-76. Tersedia pada: https://media.neliti.com/media/publications/26017 1-sistem-informasi-pengolahan-data-pembelie5ea5a2b.pdf.

Muslim, B. (2018) “ANALISIS SISTEM INFORMASI (SI) TERINTEGRASI DI PERGURUAN TINGGI (PT) (Studi Kasus: STT Pagar Alam)," Jurnal Teknologi Informasi MURA, 10(2), hal. 83. doi: 10.32767/jti.v10i2.375.

Nacheva, R. (2017) "Prototyping Approach in User Interface," 2Nd Conference on Innovative Teaching Methods, (June), hal. 80-87. Tersedia pada: https://www.researchgate.net/publication/317414 969.

Nugraha, F. dkk. (2019) "Rancang Bangun Sistem Informasi Penilaian Beban Kerja Dosen," Simetris: Jurnal Teknik Mesin, Elektro dan Ilmu Komputer, 10(1), hal. 405-412. doi: 10.24176/simet.v10i1.3312.

Nugraha, W. dan Syarif, M. (2018) "Penerapan Metode Prototype Dalam Perancangan Sistem Informasi 
Penghitungan Volume Dan Cost Penjualan Minuman Berbasis Website," JUSIM (Jurnal Sistem Informasi Musirawas), 3(2), hal. 94-101. doi: $10.32767 /$ jusim.v3i2.331.

Purnomo, D. (2017) "Model Prototyping Pada Pengembangan Sistem Informasi," J I M P Jurnal Informatika Merdeka Pasuruan, 2(2), hal. 54-61. doi: 10.37438/jimp.v2i2.67.

Rahmawati, N. A. dan Bachtiar, A. C. (2018) "Analisis dan perancangan sistem informasi perpustakaan sekolah berdasarkan kebutuhan sistem," Berkala Ilmu Perpustakaan dan Informasi, 14(1), hal. 76. doi: 10.22146/bip.28943.

Sari, R. P., Luthfi, M. dan Veren, S. (2018) “Analisis dan Perancangan Berorientasi Objek Sistem Informasi Beban Kerja Dosen menggunakan UML," Cybernetics, 2(02), hal. 202. doi: 10.29406/cbn.v2i02.1050.

Sukmaindrayana, A. dan Sidik, R. (2017) "Aplikasi Grosir Pada Toko RSIDIK Bungursari Tasikmalaya," Jurnal Manajemen Informatika, 4(2), hal. 31-40. Tersedia pada: https://www.cambridge.org/core/product/identifie r/CBO9781107415324A009/type/book_part.

Sulistyowati, A. dan Muazansyah, I. (2018) "Pengaruh
Beban Kerja Dan Kesejahteraan Dosen Terhadap Kepuasan Kerja Dan Burnout," JPAP: Jurnal Penelitian Administrasi Publik, 4(1), hal. 914919. doi: 10.30996/jpap.v4i1.1273.

Wijaya, K. (2019) "Rancang Bangun Sistem Informasi Perpustakaan Menggunakan Java (Netbeans 7.3)," 08(01), hal. 53-60.

Yoko, P., Adwiya, R. dan Nugraha, W. (2019) "Penerapan Metode Prototype dalam Perancangan Aplikasi SIPINJAM Berbasis Website pada Credit Union Canaga Antutn," Jurnal Merpati, 7(3), hal. 212-223. Tersedia pada: http://jurnal.univbinainsan.ac.id/index.php/jusim/ article/download/331/228.

\section{UCAPAN TERIMA KASIH}

Kami sampaikan terima kasih kepada Institut Teknologi Kalimantan yang telah mendukung dan telah memberikan kesempatan kepada kami pada kegiatan penelitian sebagai tenaga kependidikan. Semoga tenaga kependidikan dapat terus melakukan penelitian dan dapat diberikan kesempatan yang sebesar-besarnya untuk meneliti. 